\title{
A Secure Wireless Telehealthcare Monitoring System and its Web Application
}

\author{
Mirza Mansoor Baig ${ }^{1}$, \\ Hamid GholamHosseini ${ }^{1}$ and Dehan Luo ${ }^{2}$
}

${ }^{1}$ School of Engineering, Auckland University of

Technology, Auckland-1142, New Zealand

${ }^{2}$ School of Information Engineering, Guangdong University of Technology, Guangzhou 510006,

China

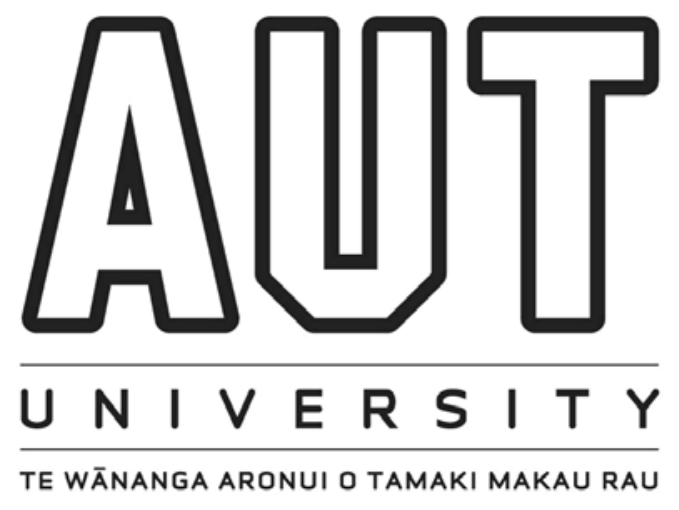

TE WĀNANGA ARONUI O TAMAKI MAKAU RAU 


\section{RESEARCH SPACE}

Hospitalize d Older Adults

Fall

Vital

Signs 


\section{RESEARCH SCOPE}

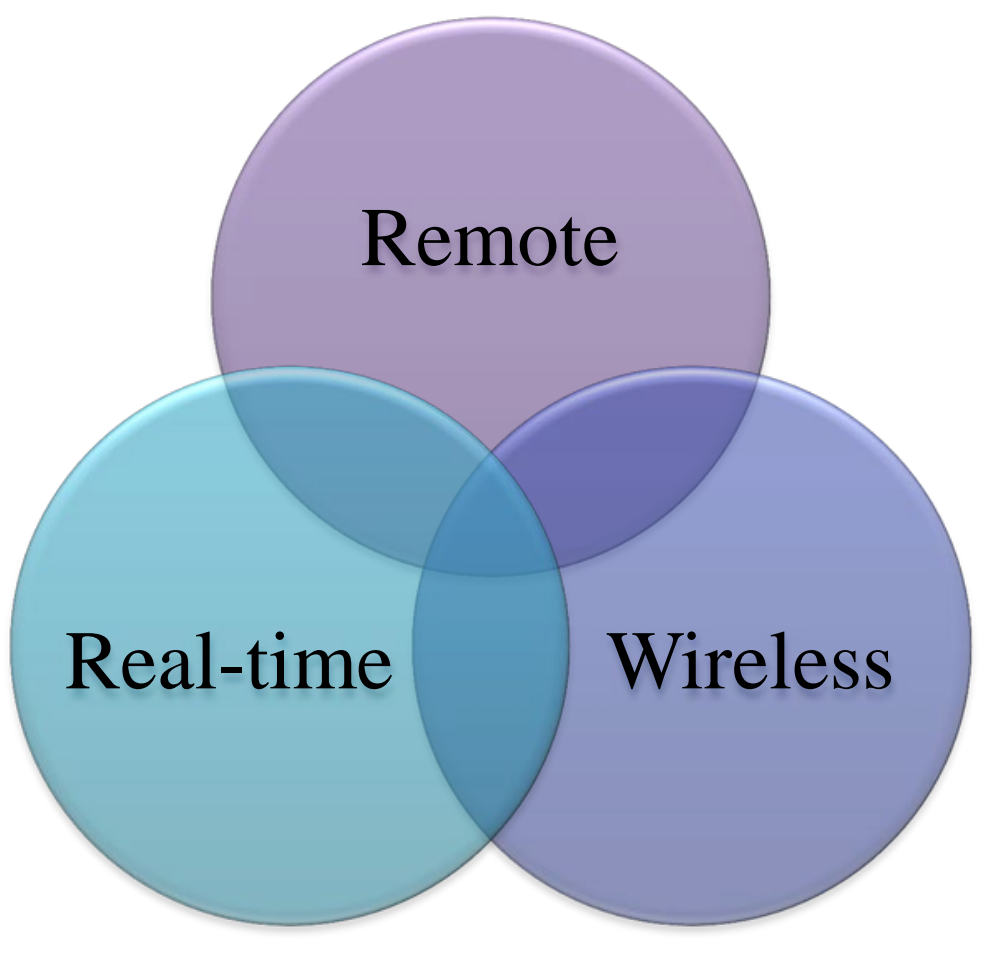




\section{Work Overview}

- Research focuses on two important areas of healthcare; real-time remote patient monitoring and wireless medical device connectivity.

- Advanced real-time, wireless patient monitoring system with two-way audio/video transmission as well as vital signs.

- Real-time testing is underway at New Zealand Hospitals. 


\section{Blood Pressure Monitor}
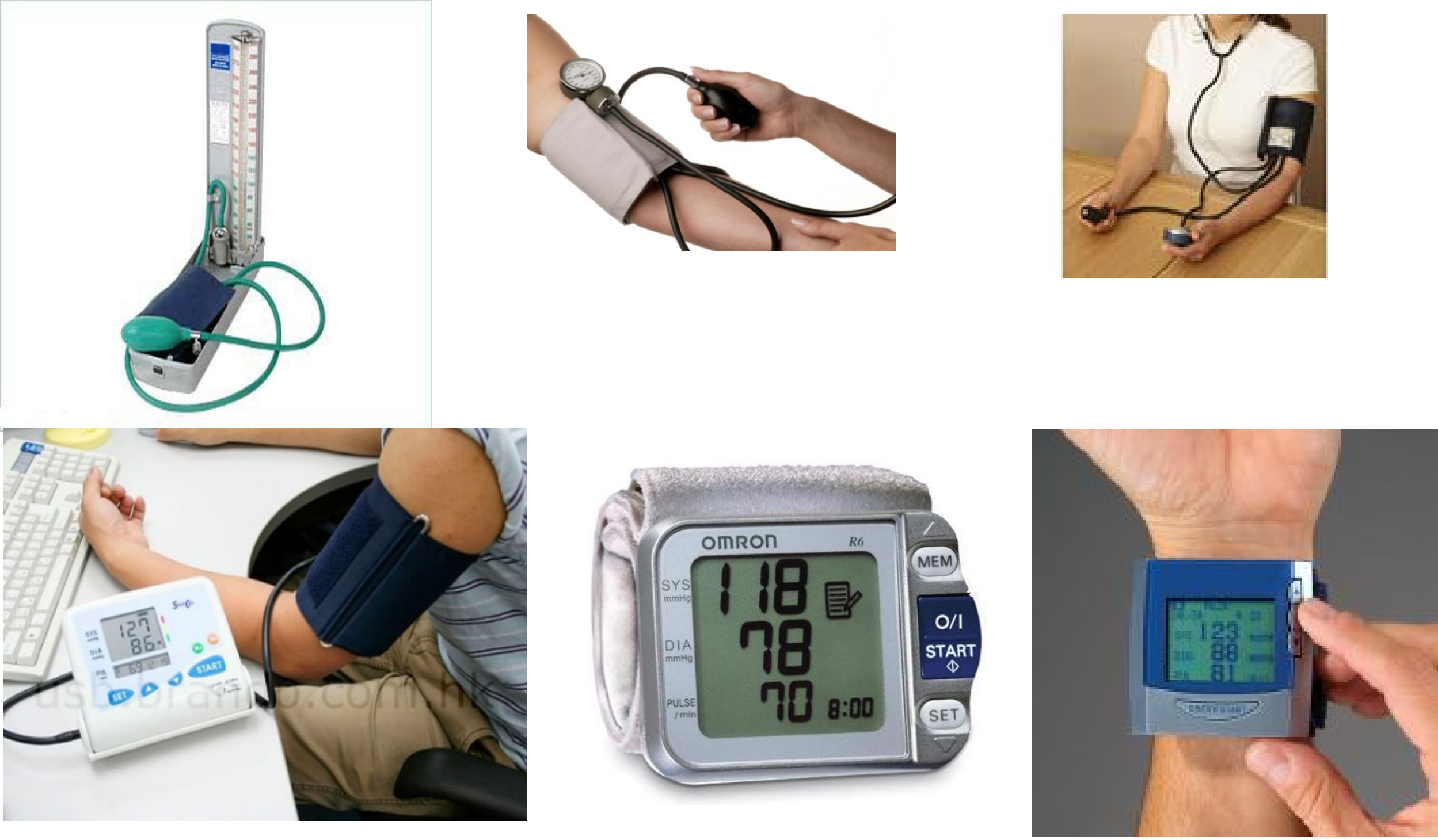


\section{Limitations and Challenges}

- Delay in alert/warning due to data transmission or real-time data processing

- Security and privacy of patient's medical data and personal identification

- Rate of false alarms generating by diagnosis systems 


\section{Block Diagram}

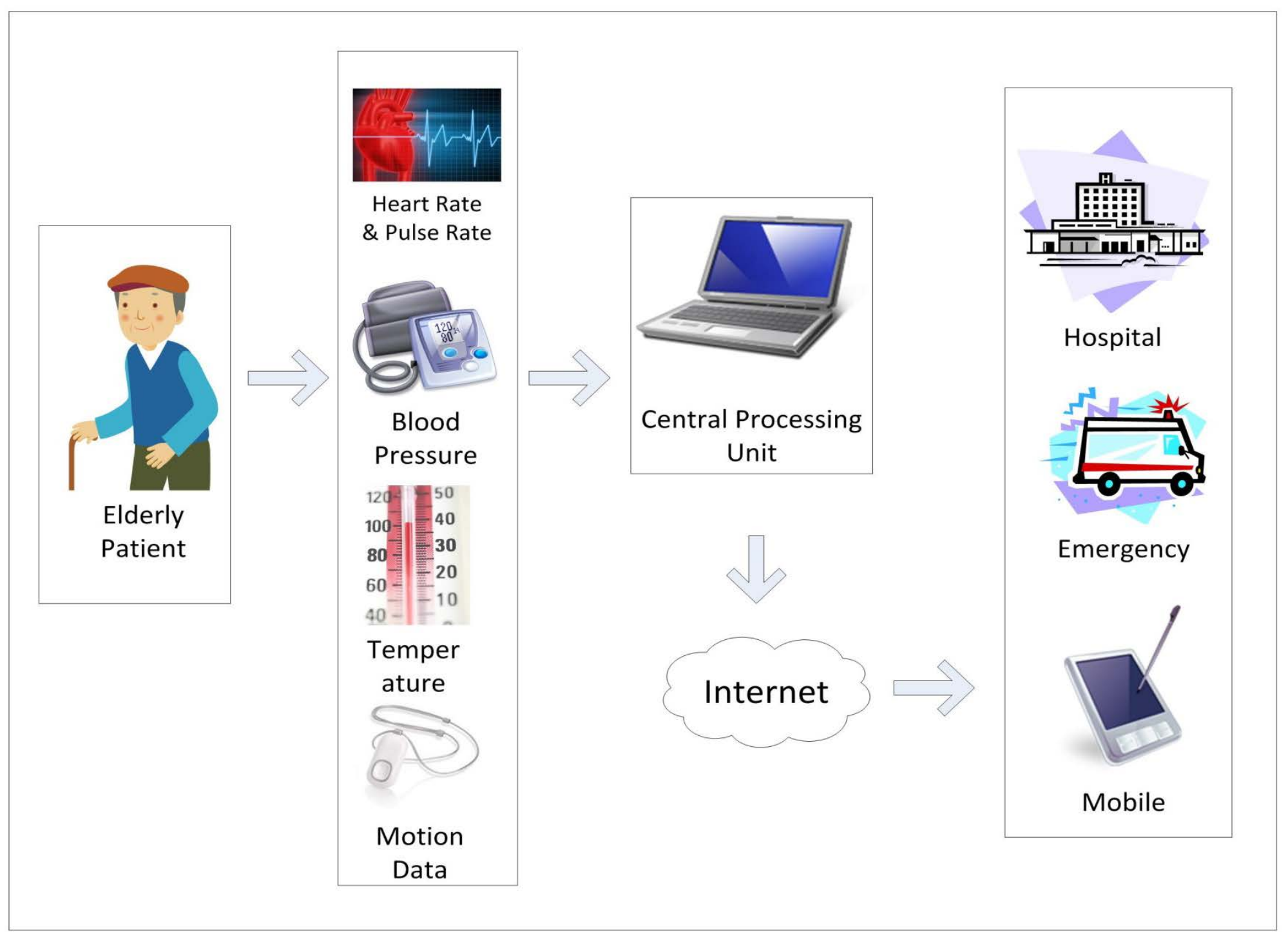




\section{Logic Diagram}

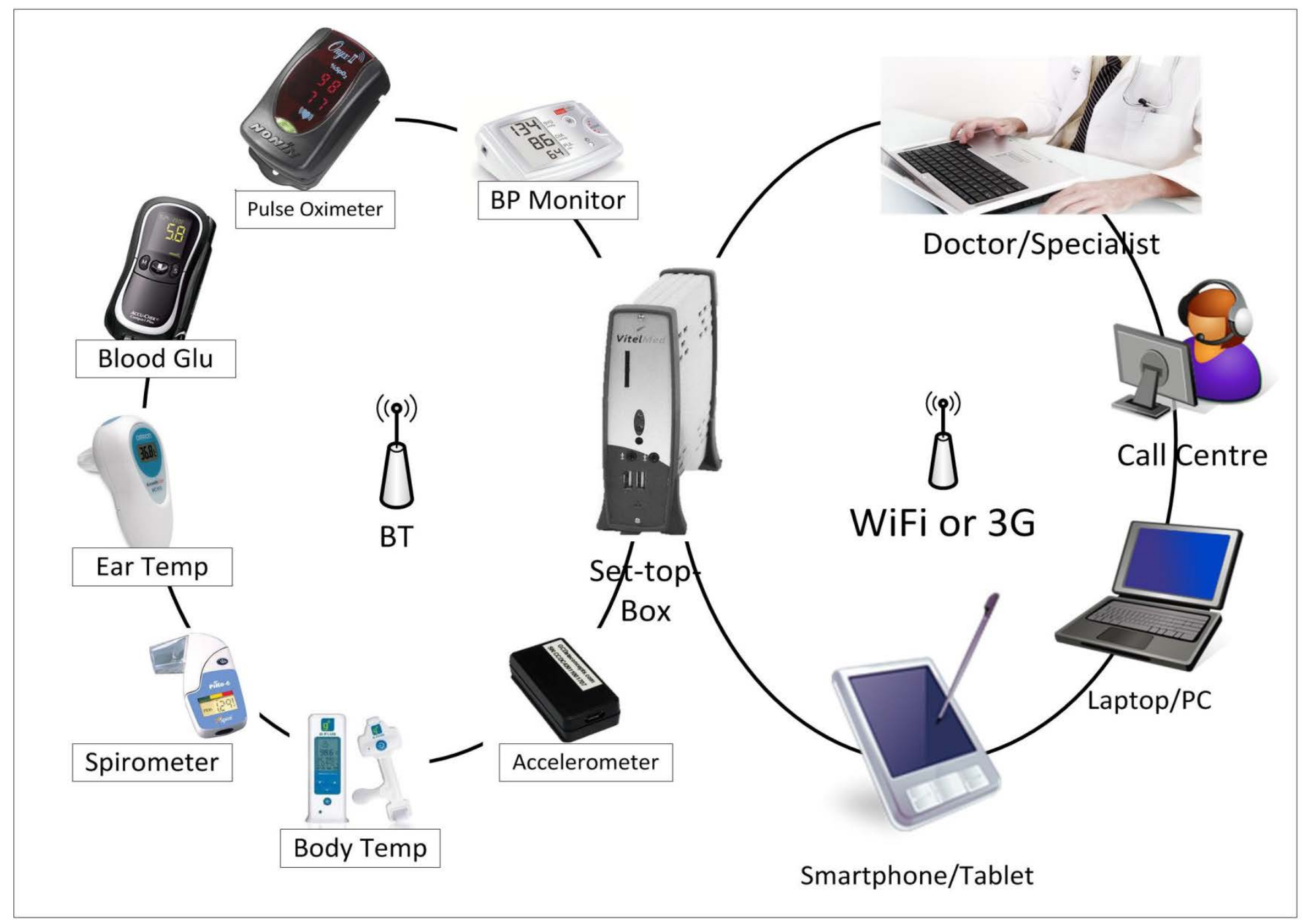




\section{Key Functionalities}

- Set-top-box-data collection and transmission

- Vital signs-ECG, heart rate monitor, blood pressure, pulse and blood glucose meter

- Two way audio-video transmission

- Secure and user friendly 


\section{The System}

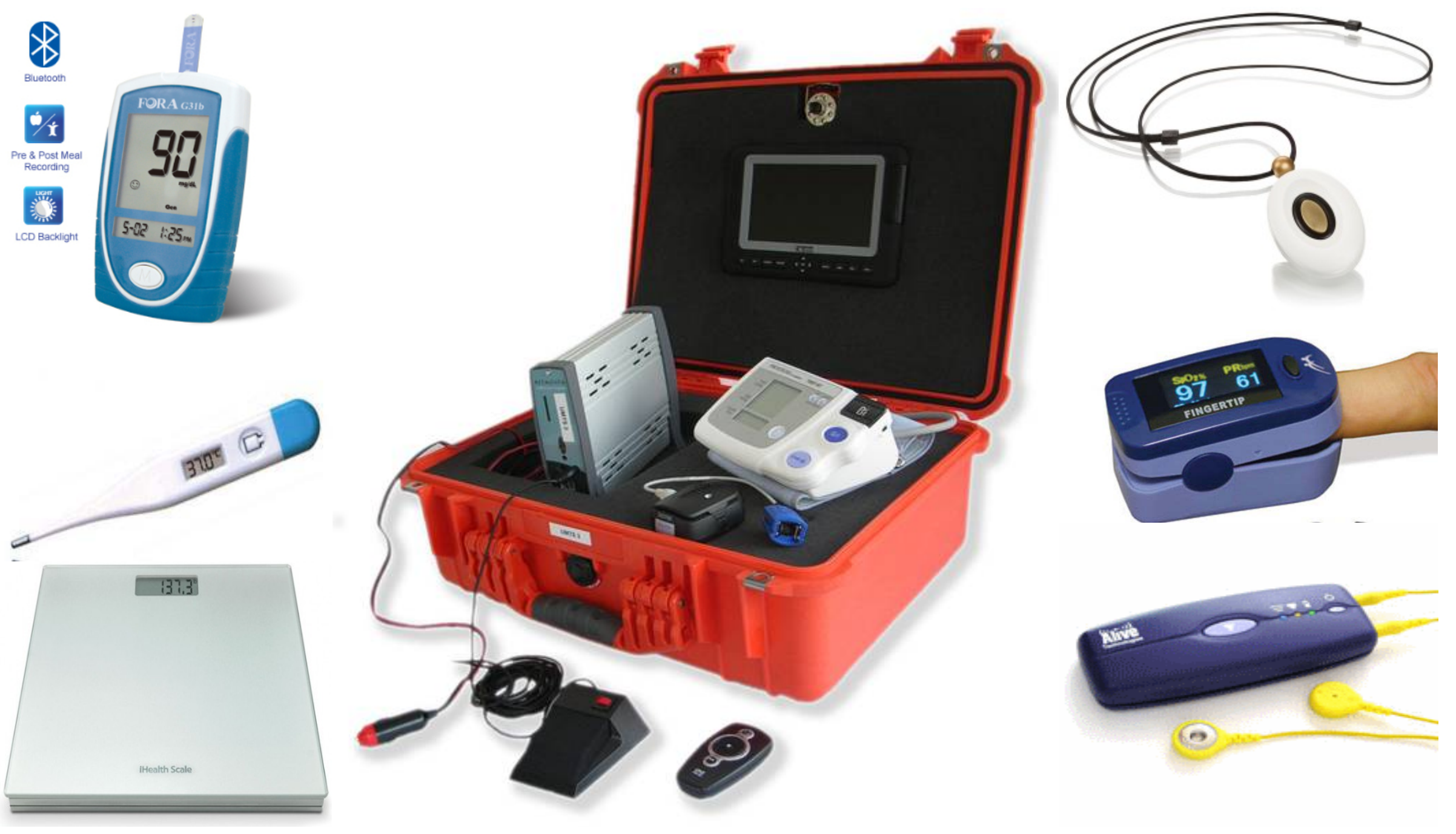




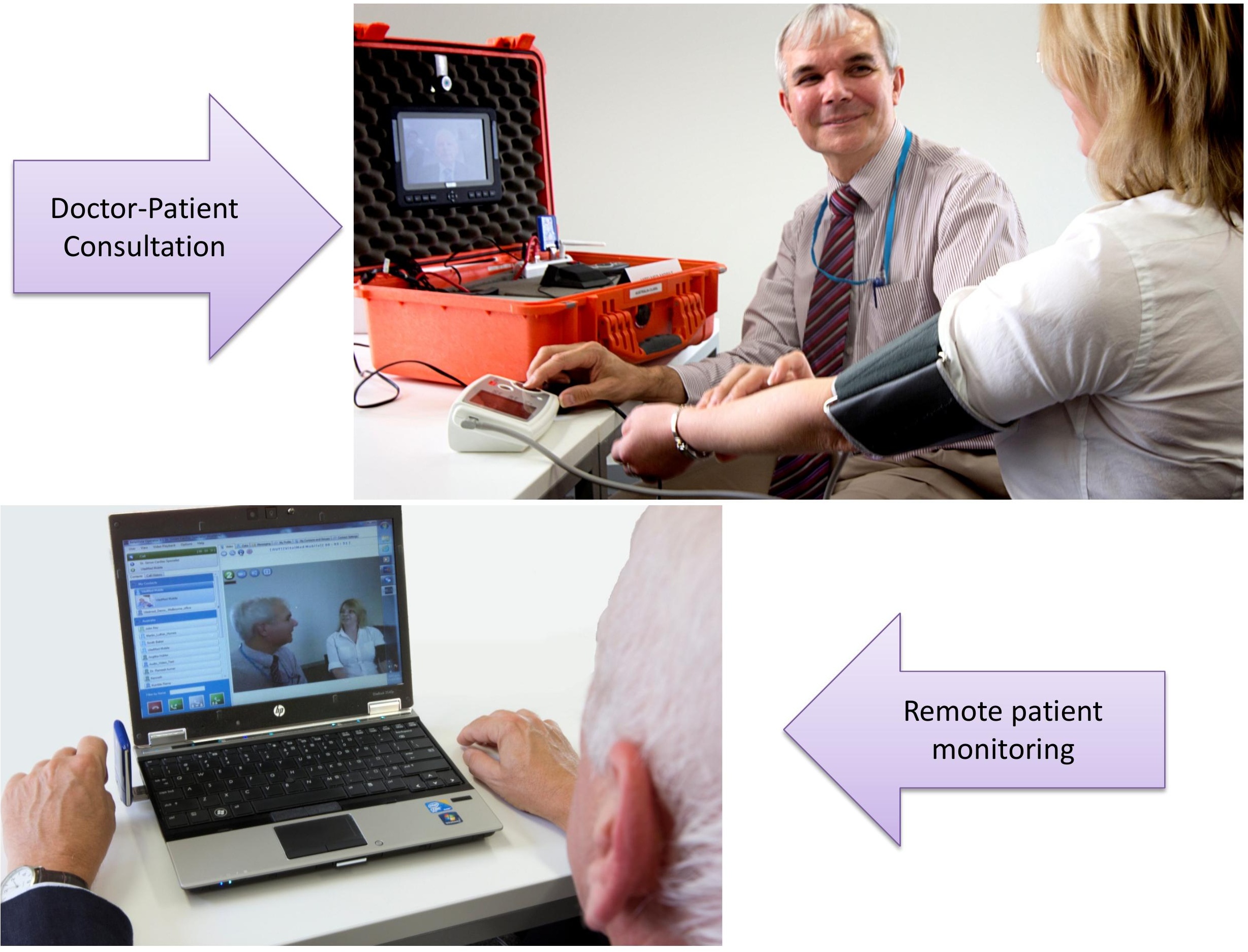




\section{The Devices}

1. Data receiver box - Set-top-box

2. Boso-medicus prestige BP Monitor

3. Nonin's Onyx II finger clip

oximeter

4. Accu-Chek Compact plus B Glu.

Monitor

5. Omron's Ear Thermometer

6. G-plus wireless remote thermometer

7. nSpire's Piko-6 spirometer

8. Gulf Coasts Data Concept's accelerometer X8M-3mini
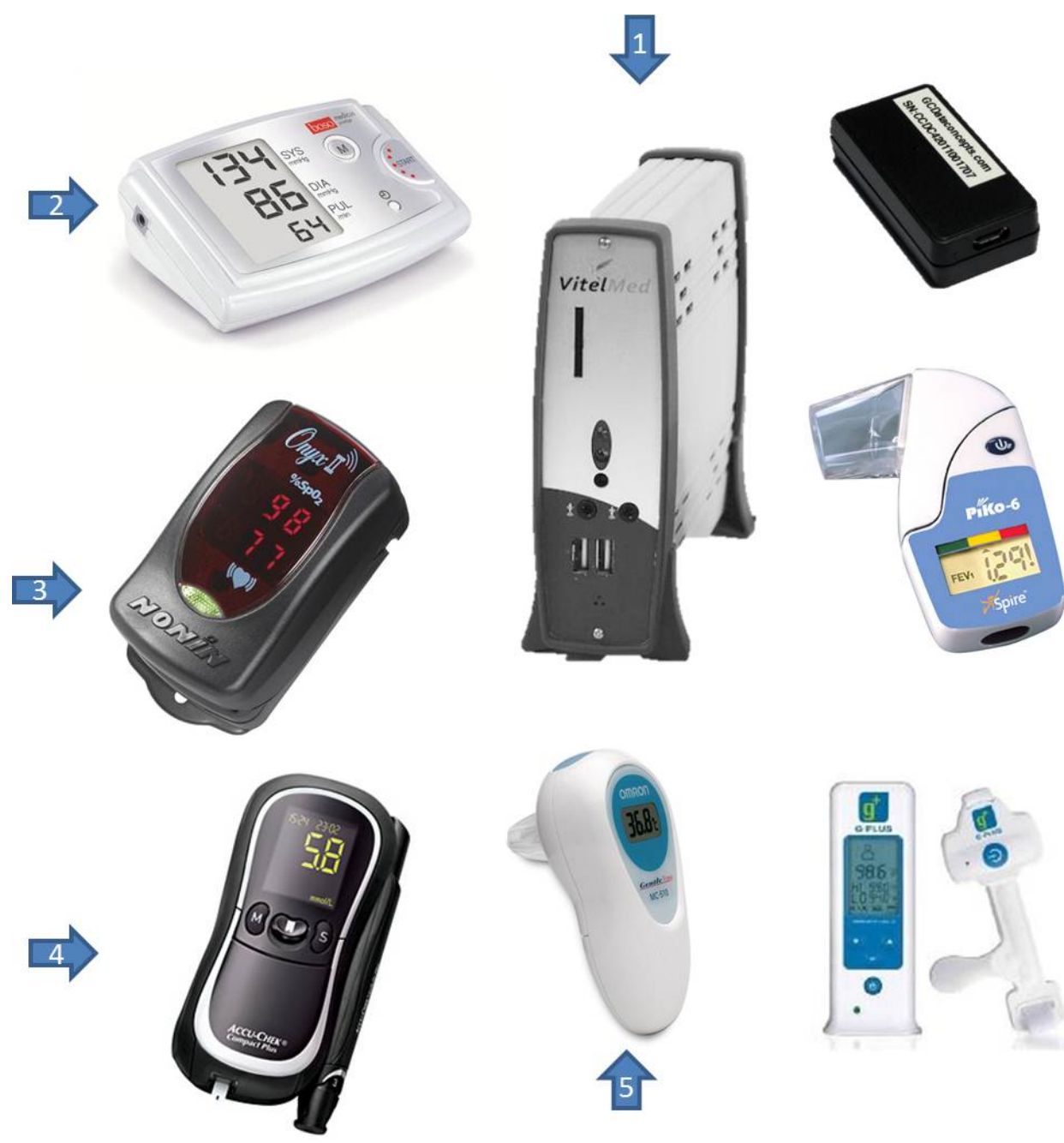


\section{○.}

88

Tablet_AU_1

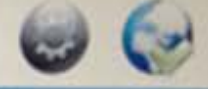

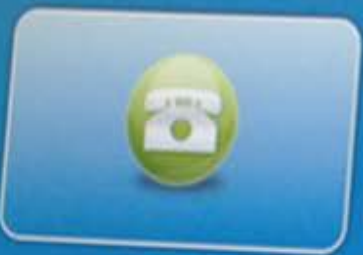

Make Call

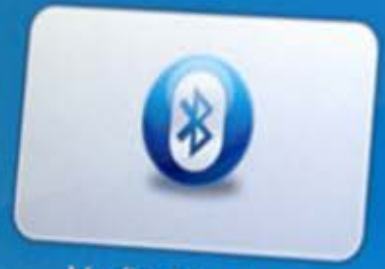

Medical Devices

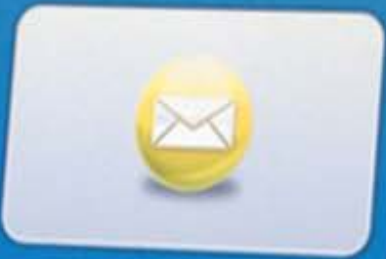

Messages

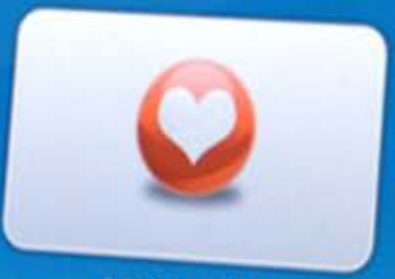

My Health

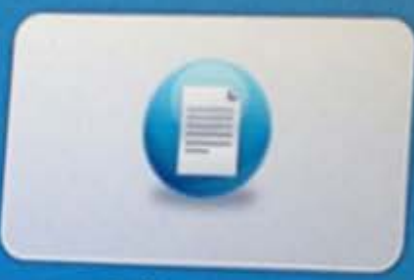

Call History

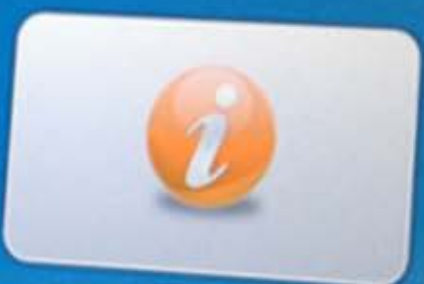

Weblinks

\section{甘}

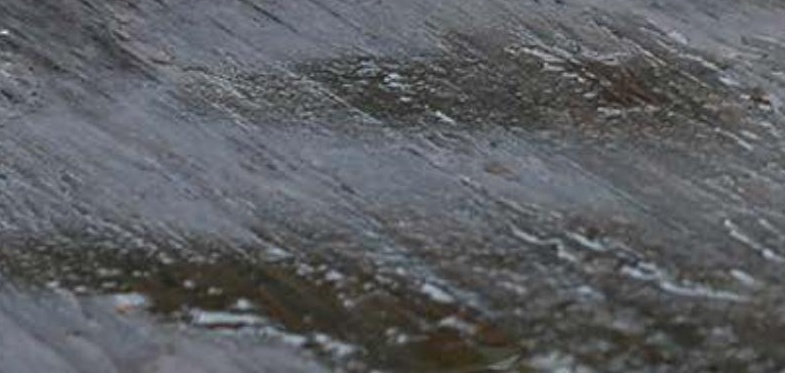




\section{Results}

- The proposed system is tested offline using approximately 200 hours of patient data.

- The performance was measured using; true positive (TP), true negative (TN), false positive (FP) and false negative (FN).

- System has achieved an accuracy of $92.60 \%$, sensitivity of $94.35 \%$, specificity of $91.92 \%$ and predictability of $81.81 \%$. 


\section{Results Summary}

\begin{tabular}{|c|c|c|c|c|}
\hline \multirow[t]{2}{*}{ Alarms } & \multicolumn{2}{|c|}{ PROPOSED SYSTEM } & \multicolumn{2}{|c|}{ Oberli et al.\# } \\
\hline & $\begin{array}{l}\text { Diagnostic } \\
\text { module }\end{array}$ & $\begin{array}{c}\text { Datex-Ohmeda S/5 } \\
\text { monitor }\end{array}$ & $\begin{array}{l}\text { Expert } \\
\text { System }\end{array}$ & $\begin{array}{c}\text { Space Labs } \\
\text { monitor }\end{array}$ \\
\hline TP & 117 & 104 & 169 & 149 \\
\hline TN & 296 & 327 & 112 & 181 \\
\hline FP & 26 & 82 & 8 & 737 \\
\hline $\mathbf{F N}$ & 7 & 35 & 24 & 88 \\
\hline Total Alarms & 446 & 548 & 289 & 1067 \\
\hline Accuracy (\%) & 92.60 & 78.64 & 89.77 & 28.57 \\
\hline Sensitivity (\%) & 94.35 & 74.82 & $87.56^{*}$ & $62.86^{*}$ \\
\hline Specificity (\%) & 91.92 & 79.95 & 93.33 & 19.71 \\
\hline $\begin{array}{c}\text { Predictability } \\
(\%)\end{array}$ & 81.81 & 55.91 & $95.48^{*}$ & $16.81^{*}$ \\
\hline
\end{tabular}

Where TP is true positive, TN is true negative, FP is false positive, FN is false negative. The authors used TP and TN to calculate the sensitivity and predictability.

\# - C. Oberli, et al., "An expert system for monitor alarm integration," Journal of Clinical Monitoring and Computing, vol. 15, pp. 29-35, 1999. 


\section{Conclusion \& Future Work}

- Our aim is to minimize current challenges and limitations, by using a remote patient monitoring system.

- Add more physiological parameters and devices.

- Currently, the proposed system is on-going clinical trial with more than 30 patient at New Zealand Hospitals. 
Thank You 